\title{
The Effect of Group Sandplay Therapy on Psychological Health and Resilience of Adolescent Survivors of Nepal Earthquake*
}

\author{
이 세 화 ${ }^{* *}$ \\ Lee, SeHwa \\ 장 미 경*** \\ Jang, Mikyung
}

\begin{abstract}
$<$ Abstract $>$
The authors analyzed the effects of group sandplay therapy on the psychological health and resilience of adolescent survivors 16 months after the 2015 Nepal earthquake, and explored the themes these adolescents expressed during counseling. Group sandplay was found to have significantly decreased the adolescents' internalizing problems such as anxiety/depression and withdrawal/depression, while their resilience had also significantly improved. The narrative analysis in turn yielded seven themes: magical wish fulfillment/hope for recovery; direct expression of danger of disaster; relationship with gods revealing human's identity; desire for protection and care from danger and damage in reality; recovering the order of life from chaos; creation of a new world from the chaotic world; and return to their normal daily life.
\end{abstract}

Keywords : group sandplay therapy, earthquake, adolescents, Nepal, resilience, Hinduism

* This paper is part of a 2016 master's thesis at Namseoul University.

** Main Author, Specialist for Sunflower Center of Chungnam for Women and Children Victims of Violence (gginmandu@hanmail.net)

*** Corresponding Author, Professor, Department of Child Welfare at Namseoul University (jangmiky@nsu.ac.kr) 
Journal of Symbols \& Sandplay Therapy, Vol.11 No.2.

\section{I . Introduction}

Sandplay is a nonverbal yet expressive approach to counseling for children and adults that was developed by Dora Kalff (1980/2003) from her study of the analytical psychology of Carl Jung (1969). In both individual and group contexts, sandplay has been shown to help participants develop the inner resilience to overcome traumatic events. Unfortunately, due to a dearth of research in this area, there remain gaps in the understanding of how to use this modality to foster resilience in adolescents.

These gaps were brought strongly to our attention during our work in Nepal with adolescent survivors of the devastating earthquake that had struck the country in April 2015. The aftermath left 8,900 people dead and over 22,000 injured. The number of homes damaged or destroyed by the disaster numbered more than 880,000 (Nepal Planning Commission, 2015), with the result that many survivors were left homeless and thus forced to seek shelter in temporary relief camps. All the adolescents we counseled had lived in the camps for 16 months and were traumatized by their experiences of the earthquake and its aftermath.

The psychological and physical health of these individuals was severely affected by factors such as leaving their homes, deprived living conditions within the camps, change or loss of occupation and income, adaptation to a new place, and uncertainty about the future, combined with the stress and anxiety caused by these factors. Psychological states after a disaster can be divided into acute, subacute, and chronic phases; the acute phase being 3-7 days after the disaster, subacute phase 1-3 months, and the chronic phase 3 months (Korean Disaster \& Trauma Mental Health Committee, 2015). Accordingly, the survivors of the Nepal earthquake can be said to be in the chronic phase characterized by emotional and behavioral problems such as post-traumatic stress symptoms, mood disorders, behavioral problems, dissociative symptoms, traumatic mood responses, and somatic symptoms - problems which, in the absence of social support, might not abate (Bal, 2008; Risler, Kintzle, \& Nackerud, 2015).

McAdams has suggested a phased approach for crisis clients, and explained that the actions required at the different phases are different (McAdams \& Keener, 2008). Furthermore, because elements such as age, gender, sexual, cultural, socioeconomic, religious and spiritual identities can affect the mental health outcome of each phase, it is necessary to take a more contextual approach to the ecosystem to which the client belongs (Ratts et al., 2016). Both of these 
approaches inform the current study, the purpose of which is to examine the effect of group sandplay therapy on the psychological health and resilience of adolescent earthquake survivors in Nepal.

\section{Resilience}

Post-traumatic stress disorder (PTSD) and other psychological health problems experienced by survivors of natural disasters such as earthquakes can be offset by a factor such as resilience (Kukihara et al., 2014; Jang \& Yoo, 2014; Stein, 2009). Resilience predicts active coping strategies ( $\mathrm{Li} \&$ Yang, 2016) and is negatively correlated with post-traumatic stress disorder symptoms (Bensimon, 2012). Hence counseling interventions that help strengthen the resilience of crisis clients are needed.

In a study of survivors of the Fukushima earthquake in Japan (Kukihara et al., 2014), it was found that resilience had reduced the impact of the trauma on the survivors. Another study reported a significant positive correlation between resilience and posttraumatic growth in adolescents (Park, 2013). There was also a correlation between the level of resilience and problems such as indirect trauma, depression, and anger among South Korean children and adolescents due to media coverage about the sinking of a large ferry that claimed the lives of 250 Korean high school students (Jung, 2015).

The ability of adolescents to recover from adversities like natural and other disasters comes from proactive factors that enhance their resilience. These factors reduce the impact of vulnerabilities or risk factors in the environment to an individual (Everall, Altrows, \& Paulson, 2006; Hauser, 1999; Rak \& Patterson, 1996). Proactive factors fall into three categories: individual, family, and external or community factors.

Individual factors that enhance resiliency include good cognitive functioning (Richman \& Fraser, 2001), good problem-solving skills, and problem-focused coping strategies (Fernando \& Hebert, 2011; Everall, Altrows, \& Paulson, 2006; Howard \& Johnson, 2000). Family factors are related to a secure attachment with at least one parent who plays a major role in promoting resilience. Parents can be supportive sources of informative support, consisting of guidance and information, and emotional support, which help adolescents develop their self-esteem (Dumont \& Provost, 1999). External or community factors involve the support of caring nonparent adults 
Journal of Symbols \& Sandplay Therapy, Vol.11 No.2.

such as teachers, counselors, ministers, and neighbors (Walsh, 2002). Adolescents from troubled families, or whose parents do not have the ability to support them due to a natural disaster or lack of community resources, are especially in need support from a counseling group (Wang, Nan, \& Zhang, 2017; Lee et al., 2013; Salloum et al., 2009; Everall, Altrows \& Paulson, 2006).

\section{Psychological Health}

Adolescents are in a developmental phase in which they struggle with issues regarding their independence/dependence in relation to their parents. Adaptation to a temporary living environment such as a relief camp after a disaster amplifies the adolescent's sense of loss and causes considerable stress, often accompanied by anger and grief and the disconnection from familial relationships raises societal tension (Bae, 2016). In addition, the stress of parents' psychological difficulties, such as unemployment and environmental changes, places a double burden on the adolescents, who may find themselves expected to behave more maturely than their normal developmental stage (Hwang \& Kim, 2017).

These factors can lead to family conflict, and cause adolescents to internalize their stress caused by the disaster and this can also be externalised as behavioral problems. The symptoms can also be somatized in the form of headaches, rashes, and gastrointestinal disorders, as well as leading to sleeping and eating disorders, sexual dysfunction, loss of concentration, low energy, depression, anxiety, and helplessness (Gu, 2011). Children and adolescents might also experience PTSD symptoms similar to adults, such as flashbacks, nightmares, avoidance, numbness, and social withdrawal (Furukawa, Takeuchi, Yano, \& Muto, 2015; Oyama, Nakamura, Suda, \& Someya, 2012).

Research has found that the prevalence of PTSD symptoms among adolescent survivors of earthquakes is high; a study identified these symptoms in 10-80\% of those aged 12-15 years who survived the 1999 Izmit earthquake in Turkey (Yoyorb, Akbiyik, Kirmizigul, \& Sohmen, 2004). Another study, of 101 adolescents after the 2011 Tohoku earthquake in Japan, showed that $15.6 \%, 51.4 \%$, and $18.7 \%$ of participants reported clinical levels of depression, anxiety, and PTSD (Okuyama et al., 2017). A major study of 2,299 Chinese adolescents 3 and 6 months after the 2013 Lushan earthquake revealed that the prevalence rates of probable PTSD were 
$37.4 \%$ and $24.2 \%$, respectively, and indeed the prevalence rate of all somatic symptoms was higher than 50\% (Zhang, Zhu, Du, \& Zhang, 2015).

Children and adolescents from developing countries, such as Nepal, struggle to recover from the psychological stress and trauma of a natural disaster and their recovery time tends to be prolonged (Bal, 2008). Family support is often lacking as the parents also experience psychological problems after a disaster (Morris, Gabert-Quillen, \& Delahanty, 2012); a vacuum that is further compounded by the inadequate mental care services of these countries (Deeba \& Rapee, 2015), especially in rural areas.

\section{Psychological Intervention after the 2015 Earthquake in Nepal}

It is fair to say there is a serious dearth of psychosocial services in Nepal for acute or prolonged PTSD in the wake of natural and other disasters. Following the 2015 earthquake, the government did deliver a number of mental health services, including a 24/7 counseling hotline, training for healthcare workers to provide basic mental health service in clinics and hospitals, and a screening tool to assist health volunteers diagnose and refer to the most acute cases. However, none of these initiatives were provided at a professional level (Sherchan et al, 2017).

This state of affairs is unsurprising if one considers the 2006 Nepal report released by the World Health Organization on Nepal, which estimated that the number of mental health professionals per 100,000 people was just 0.59, with a disproportionately higher density in urban versus rural areas, with government spending on mental health accounting for a meager $0.17 \%$ of the total health budget (WHO, 2006). Moreover, the state of counselor education in Nepal is meager: Training courses are short, do not involve clinical practice, and are provided on a private level by foreign experts unfamiliar with the cultural setting (Jordans, Keen, Pradhan \& Tol, 2007).

At the time the Nepal report was compiled there had been no reported cases of adolescent patients actually using the available mental health services and facilities (WHO, 2006). This is especially concerning as another, later report estimates that $38 \%$ of adolescents in Southeast Asian countries have suicidal ideation, suicidal ideation with a plan, or have attempted suicide (WHO, 2017); this is with or without natural disasters involved. Among the rare research conducted in the wake of the 2015 Nepal earthquake, a study on the post-traumatic stress 
Journal of Symbols \& Sandplay Therapy, Vol.11 No.2.

symptoms (PTSS) of 893 adolescents aged 11-17 revealed that the prevalence of PTSS in the Sindhupalchok district was $39.5 \%$, and depression symptoms was $40.0 \%$, which was $2-3$ times higher than those of adolescents in the capital, Kathmandu (Silwal et al., 2018).

So far, the studies related to the 2015 Nepal earthquake have focused on the impact of the disaster on the people's psychological health, and there has yet to appear any studies reporting the effectiveness of intervention programs. Gathering essential data to provide rapid and effective intervention to populations devastated by the effect of natural disasters involves many obstacles (Morton \& Levy, 2011); these include the lack of professionals and infrastructure social systems, cultural barriers, and misunderstanding of the need for psychological intervention. Additionally, there are difficulties in communication, especially with adolescents who have lost parents to disasters or who have psychologically or physically unhealthy parents, or have parents who want their children to work instead of participating in the intervention programs due to family economic hardship.

\section{Sandplay}

People who practice the Hindu religion in Nepal may be reticent to express negative emotions due to their belief in reincarnation, which they believe is determined by good or bad actions in this lifetime (Tanwar, 2016; Han, 2010). Therefore, it may be more effective to provide nonverbal and creative outlets for crisis intervention such as sandplay therapy rather than more traditional forms of direct verbal expression (Yeh, Aslan, Mendoza, \& Tsukamoto, 2015). As such, sandplay therapy might be a useful way of strengthening resilience against the impact of a natural disaster such as an earthquake and mitigating against mental health problems.

Sandplay combines both art and play therapy and is an ideal approach for young people in particular, whose verbal skills are usually less developed than those of adults (Reece \& Ford, 2006) and who tend to find it more natural to express themselves through play than through language (Landreth, 2012). Sandplay therapy engages with the archetypal level of the psyche in order to produce meaningful and lasting change in an individual (Bradway et al, 1980/1990).

Sandplay also can be applied to groups, and there are two reasons why this approach was developed. One reason was the growing numbers of disturbed children in communities with limited budgets for individual treatment (Taki-Reece \& Ford, 2006) and secondly was the 
necessity for family-oriented intervention (Carey, 1999). Group sandplay therapy has proven to be an effective approach for several populations (Ebershohn \& Loots, 2017; Hwang, 2017; Zhang, 2017; Jang \& Kim, 2012), although the quantity of research is limited and research designs are not objective.

Organizing groups of people exposed to the same trauma event and encouraging them to share their experiences can be a highly effective form of counseling. (Hong, 2005). It also acts as another form of support group (Salloum et al, 2009). This process of sharing can reduce feelings of isolation and negative emotions caused by the trauma, as well as allow a social comparison of traumatic wounds, through which a reduction in anxiety can occur (Park et al., 2014). Sandplay therapy for children was proven to be effective as a crisis response to the September 11 attacks (Yeh, Aslan, Mendoza, \& Tsukamoto, 2015).

Studies on the effectiveness of sandplay therapy for child and adolescent victims of natural and other disasters remain somewhat limited: There are three studies related to sandplay and its effectiveness in this area; firstly a study that conducted sandplay therapy with Nepal earthquake survivors found that it relieved the impact of events and post-traumatic stress symptoms on them (Hwang, 2017). Another study administered group sandplay therapy to survivors of the 2008 Sichuwan earthquake in China, though the latter was not based on objective research designs (Shen \& Lan, 2011). There was also a study that provided sandplay therapy for US soldiers and their families who had been diagnosed with PTSD after service in Iraq and Afghanistan (Moon, 2006).

Existing studies that have examined the effectiveness of psychological intervention for child and adolescent survivors of natural and other disasters usually involved Trauma-Focused Cognitive Behavioral Therapy (TF-CBT) or play therapy. This is consistent with a study on the treatment of PTSD for adult survivors of natural disasters that found Eye Movement Desensitization and Reprocessing (EMDR) and TF-CBT to be effective (Seidler \& Wagner, 2006). However, the TF-CBT approach may not be suitable for those with learning disabilities or with mental health problems such as anxiety and depression, and is criticized for not addressing the underlying causes because it focuses only on current or specific problems (Feeny et al, 2004). In addition, in the EMDR process, traumatic events that cause PTSD are re-experienced, and if they persist even after the session is over, other aspects of the PTSD of client's life may be disrupted (DiGiorgio et al, 2004). These problems of TF-CBT and EMDR can be compensated only when 
Journal of Symbols \& Sandplay Therapy, Vol.11 No.2.

psychotherapy approaches, such as sandplay therapy, should be provided or at least should be combined with them. Sandplay therapy has turned out to be effective in treating severe anxiety such as traumatic brain injury, PTSD with depression, substance abuse, and mental health such as dissociative disorder (Zappacosta, 2013; Garza, Monakes, Watts \& Wiesner, 2011; Plotts, Lasser \& Prater, 2008; Reyes, 2003; Mathis, 2001).

Sandplay therapy was historically created as a form of play therapy and so referring to existing play therapy studies allows us to confirm the effects of sandplay therapy, albeit indirectly. Relevant examples include a study on survivors of 1992's Hurricane Andrew which found that children were able to express their traumatic experiences and restore mastery and power through play (Shelby \& Tredinnick, 1995). A survey that was conducted amongst counselors who have treated PTSD discovered that the best practice for these counselors was play therapy(Marotta, 2000). Similarly, a meta-analysis of the effectiveness of TF-CBT and play therapy for child victims of abuse discovered that both forms of counseling produced more favorable results than the comparison groups in that study. Play therapy has been found to be more effective on externalizing problems, but if the child has additional problems then TF-CBT would be more effective (Slade \& Warne, 2011).

\section{П . Method}

\section{Participants}

The subjects of this study were adolescent survivors of the 2015 Nepal earthquake who were residing in a temporary relief camp in the capital, Kathmandu. The Nepalese language version of the Child Behavior Checklist 6-18 (CBCL 6-18) was administered to a total of 200 adolescents aged 14-17 years, 119 (59.5\%) of whom belonged to the potential risk group (i.e., who had a total score of 63 or higher on the total internalizing problems of the CBCL 6-18, or borderline clinical range). Their mean age was 15.2 years old. From this category, 12 adolescents (10.1\%) consisting of six males and six females were recruited on a first come, first serve basis as participants, divided equally between the experimental and control groups.

Initially, 14 adolescents applied to be part of the sandplay intervention program and 12 were 
able to participate. To overcome difficulties in obtaining parent or guardian consent post-natural disaster, the researchers visited each adolescent's parent or guardian and explained the purpose, procedure, and confidentiality issues in order to obtain their consent. Twelve parents agreed that their children could participate in sandplay. One parent refused permission for participation and another parent was unavailable to discuss the situation at several pre-arranged visits.

Most of the participants identified as Hindu, except for one Christian and one Buddhist in the experimental group, and two Buddhists and one Christian in the control group. The mean ages of the experimental and control groups were 15.6 and 15.5 years, respectively.

\section{Ethical Considerations}

We provided participants and their parents or legal guardians with written material containing clear and simple explanations regarding the purpose of the study, the methods used to analyze the data, and the confidentiality of their information. Written informed consent was obtained from all participants and their parents or legal guardians. Furthermore, the project was approved by the Kathmandu Metropolitan City Office and Namseoul University's Institutional Ethics and Life Committee (Code: NSU-161115-09).

\section{Measures}

\section{1) $\mathrm{CBCL}-6-18$}

For this study, the Nepalese language version of the Child Behavior Checklist 6-18 (CBCL 6-18), was used. This checklist was completed by the primary caregiver and measures the social adjustment and the emotional and behavioral problems of children aged 6-18 years. It contains 113 items in total for assessing behavioral problems, some of which can also be used to assess post-traumatic stress disorder, dissociation, or both.

In this study, only items assessing internalizing problems (anxiety/depression, withdrawal/ depression, and somatic complaints), which are known to be prominent during the chronic period after a natural disaster, were included (Jiang et al., 2016; Davidson \& McFarlane, 2006). The total number of items in the internalizing domain was 32, and each was rated on a 3-point scale ranging from 0 to 2 . A total score of 60-63 indicates the borderline clinical range, and a 
Journal of Symbols \& Sandplay Therapy, Vol.11 No.2.

score of above 64 indicates the clinical range; in this study, the Cronbach's alpha of the internalizing problems scale was .82 .

\section{2) Resilience Scale- 25}

The Resilience Scale-25 by Wagnild and Young (1993) was used to investigate the resilience of adolescent survivors of the Nepal earthquake; it comprises 5 subdomains: self-reliance, purpose, equanimity, perseverance, and authenticity. Each item is rated on a 7-point scale ranging from 1 (disagree) to 7 (agree). The total score ranges from 25 to 175 , with 145 or higher indicating high resilience, 116-144 indicating normal resilience, and 115 indicating low resilience; the Cronbach's alpha of this scale was .92 .

At the time of the study there was no Nepalese version of Resilience Scale-25 therefore, after determining that the sample was suitable for factor analysis (based on the Keiser-Meyer-Olkin measure of sampling adequacy and Bartlett's test of sphericity; $\mathrm{KMO}=.74$; Barlett's test: $\chi 2$ $(300)=818.08, \mathrm{p}<.001)$, a factor analysis was performed on this scale. Five factors were confirmed, as found in the original version and accounted for $71.07 \%$ of the total variance.

\section{Procedure}

Before starting the group sandplay therapy, the parents or guardians of adolescents who agreed to participate in the study were interviewed during an intake session. From them we obtained some information about each participant such as a growth and development history or noting any particular problems during childhood. The observations were conducted during July to August, 2015 in a building erected by UNICEF in the middle of the temporary relief camp, Kathmandu.

The pre-test, which involved administering the $\mathrm{CBCL}$ and Resilience Scale, was performed during this intake session. The group sandplay therapy comprised seven 90-minute sessions delivered three times per week. After the experimental group had completed the sandplay therapy, the same program was applied to the control group. The post-test was performed immediately following the last sandplay session.

The participants were divided into a male group of 6 participants and a female group of 6 participants; the groups were further sub-divided into pairs, making three pairs in each group. 
To ensure we adhered to Dora Kalffs sandplay therapy modality (2003), a sandtray was provided to each pair in each group. One participant created a sand scene and then shared their views, after which the other participant created a scene in a new sandtray and the process was repeated. Once everyone had finished, the whole group talked about their sandplay experiences together.

The entire sandplay therapy process, including making and talking about the sand scenes, was conducted through a non-directed approach. Every session was video recorded, and the final sand scenes at the end of each session were photographed.

\section{Research Design}

In order to maintain "the meaning and the understanding" of qualitative research, while still retaining a quantitative approach to the phenomenon: this study adopted a mixed method research design. In particular, the triangulation design of Creswell and Plano-Clark (2007) was used; this is a method that collects and analyzes quantitative / qualitative data simultaneously, as opposed to sequentially. This meant that quantitative tests were conducted both before and also after the sandplay process, rather than as a result or prior data before the qualitative research.

To collect qualitative and quantitative data simultaneously, the researchers and a translator discussed the video recordings, sand pictures, and written recordings of each participant and made some comparisons with the pre-test scores of the CBCL and Resilience Scale after each session and reflected on them in order to aid understanding for the next session. Furthermore, the pre-test scores and sandplay phenomena in each session were reviewed along with the post-test scores. This method emphasizes the equal value of quantitative and qualitative methods in achieving the research objectives, and it is similar to the concurrent triangulation by Green and his colleagues (1989).

It is vital to place an equal weight on both qualitative and quantitative data as both the process and the outcome are important in a group approach to counseling (Shannonhouse, Barden, \& McDonald, 2017). Hence the pre-test and the post-test for the mean score were obtained by using the $\mathrm{CBCL}$ and Resilience Scale prior to and following the group sandplay therapy. Here, a narrative analysis was added for an in-depth understanding of the causes, 
Journal of Symbols \& Sandplay Therapy, Vol.11 No.2.

effects, and processes of the sandplay.

\section{Quantitative Data Analysis}

To analyze the effects of the group sandplay therapy, statistical analysis was performed using SPSS Statistics 23.0. A Mann-Whitney $U$ test was carried out to test the homogeneity of the experimental and control groups. A Wilcoxon signed-rank test was performed to examine the differences between the pre- and post-test scores of each group and to verify the effects of the intervention.

\section{Qualitative Data Analysis}

In addition to our quantitative analysis on psychological health and resilience, we performed a narrative analysis of the sandplay therapy process and participants' verbal expressions about each sand picture in order to add further information about the validity of the sandplay therapy intervention. Each sandplay session was recorded by three cameras and photos were taken of all sandtrays after each session. After each session was completed, the researchers repeatedly read the session transcripts, watched the recordings and viewed the sand pictures (with the translator also involved in this process). Then the researchers coded the narratives of the participants. The diffuse or convergent tendencies of the narrative themes were summarized through various verbal and visual means of expression (Johnson, 2004). A list of common preliminary categories was constructed, which were then narrowed down into funnels to identify the story and derive common themes (Bogdan \& Biklen, 2006).

\section{Rigor of Research}

The researchers in this study strove for persistent observation and prolonged engagement during the sandplay sessions (Lincoln \& Guba, 1985). Such efforts were consistent with the basic principles of sandplay therapy, namely excluding a counselor's subjective involvement as much as possible and reaching conclusions through the participant's statements and involvement (Kalff, 1980/2003). A researcher who did not have the role of a counselor participated in all of the 
sessions as an observer, and a translator was also on hand to help those participants who experienced communication difficulties.

The study relied on Lincoln and Guba's criteria of credibility, transferability, dependability, and confirmability (1985). For credibility the study used information from multiple sources, including video records of counseling sessions, counselors' subjective statements, and participants' drawings and sand pictures. In the final session, the researchers discussed the sand pictures and the issues that came up in the counseling sessions with the participants, which enhanced the credibility of the findings. As for transferability, the researchers employed the technique of thick description so that not only they but also the participants and readers could relate to the findings. Lastly, for dependability and confirmability, the study was subject to peer supervision involving mental health professionals, who in turn checked the content and process of counseling, as well as a discussion with two external researchers about the data categorization and main themes. In addition, debriefing sessions (Lincoln \& Guba, 1985) were held. From the initial data collection to the deduction of the final themes, the researchers attempted to eliminate any preconceptions by parenthesizing the subjective perceptions, such as their existing perceptions and beliefs, and instead strove to maintain an objective attitude.

For data interpretation, the study relied on categorical aggregation and direct interpretation (Stake, 1995; Creswell, 2007). In other words, the researchers attempted to derive meaning by making direct interpretations for individual cases using categorical aggregation and direct interpretation. The study collected instances and found meaning from repeated phenomena until it could be established that various cases belonged to a single type.

To ensure inter-rater reliability, three raters, including the researchers, collaborated in the narrative analysis. One of the raters was a Nepalese sandplay therapist living in Korea, which greatly enhanced the researchers' understanding of Nepalese culture. All three participants listed a total of 32 sub-themes, which were in turn refined down to 7 dominant themes, and subsequently reexamined by three fellow sandplay therapists through a peer debriefing session (Bogdan \& Biklen, 2006; Lincon \& Guba, 1985). From data collection to the deduction of the final 7 themes, the study attempted to eliminate any preconceptions during the entire process by parenthesizing the subjective perceptions, such as the researchers' existing perceptions and beliefs, and trying to maintain an objective attitude instead. 
Journal of Symbols \& Sandplay Therapy, Vol.11 No.2.

\section{Results}

\section{Psychological Health of Adolescent Survivors of the Nepal Earthquake}

At post-test, there were significant decreases in the subdomains of anxiety/depression $(Z=-3.08, p<.01)$, withdrawal/depression $(Z=-2.41, p<.05)$, and somatic symptoms $(Z=-3.07$, $p<.01)$, as well as the total score $(Z=-3.06, p<.01)$. There was also a significant decrease in the withdrawal/depression scores of the control group at post-test. The total mean score of the internalizing problems was $57.42(\mathrm{SD}=5.48)$, which was lower than the cut-off of 63 , indicating potential risk. Thus, participation in the group sandplay therapy alleviated the mental health problems of the adolescent survivors of the Nepal earthquake (Table 1).

Table 1. Differences in Psychological Health $(N=12)$

\begin{tabular}{|c|c|c|c|c|}
\hline Subdomain & Group & $\begin{array}{c}\text { Pre } \\
M(S D)\end{array}$ & $\begin{array}{c}\text { Post } \\
\text { M (SD) }\end{array}$ & $Z$ \\
\hline \multirow{3}{*}{$\begin{array}{l}\text { Anxiety/ } \\
\text { depression }\end{array}$} & Experiment & $61.42(4.85)$ & $54.58(4.64)$ & $-3.08^{* *}$ \\
\hline & Control & $63.50(6.45)$ & $63.08(7.54)$ & -.78 \\
\hline & $Z$ & -.90 & & \\
\hline \multirow{3}{*}{$\begin{array}{l}\text { Withdrawal/ } \\
\text { depression }\end{array}$} & Experiment & $60.25(6.47)$ & $55.50(3.00)$ & $-2.41^{*}$ \\
\hline & Control & $62.08(7.06)$ & $60.75(6.66)$ & $-2.12^{*}$ \\
\hline & $Z$ & -.29 & & \\
\hline \multirow{3}{*}{ Somatic symptoms } & Experiment & $67.42(6.61)$ & $60.83(6.82)$ & $-3.07^{* *}$ \\
\hline & Control & $69.17(3.56)$ & $69.50(3.66)$ & -.43 \\
\hline & $Z$ & -1.37 & & \\
\hline \multirow{3}{*}{$\begin{array}{l}\text { Total internalizing } \\
\text { problems }\end{array}$} & Experiment & $65.58(3.80)$ & $57.42(5.48)$ & $-3.06^{* *}$ \\
\hline & Control & $67.42(3.42)$ & $66.67(4.79)$ & -1.04 \\
\hline & $Z$ & -1.33 & & \\
\hline
\end{tabular}

${ }^{*} p<.05, \quad{ }^{* *} p<.01$ 


\section{Resilience of Adolescent Survivors of the Nepal Earthquake}

The resilience subdomains of self-reliance $(Z=-2.92, p<.01)$, purpose $(Z=-3.00, p<.01)$, equanimity $(Z=-2.95, p<.01)$, perseverance $(Z=-3.07, p<.01)$, and authenticity $(Z=-3.07, p<.01)$, as well as the total $\operatorname{score}(Z=-3.06, p<.01)$ significantly increased. In particular, the total score for resilience increased from 83.67 at pre-test to 115.00 at post-test. Although the score of 115 was still within the low resilience range, it was near the threshold of 116 points, which corresponds to a normal resilience level. These results suggest that the group sandplay therapy improved the resilience of those adolescents in the experimental group (Table 2).

Table 2. Differences in Resilience $(N=12)$

\begin{tabular}{|c|c|c|c|c|}
\hline Subdomain & Group & $\begin{array}{c}\text { Pre } \\
\text { M (SD) }\end{array}$ & $\begin{array}{c}\text { Post } \\
\text { M (SD) }\end{array}$ & $Z$ \\
\hline \multirow{3}{*}{ Self-reliance } & Experiment & $16.67(6.39)$ & $22.33(4.60)$ & $-2.92^{* *}$ \\
\hline & Control & $14.92(6.50)$ & $15.17(6.22)$ & -1.34 \\
\hline & $Z$ & -.75 & & \\
\hline \multirow{3}{*}{ Purpose } & Experiment & $18.58(6.05)$ & $24.08(5.87)$ & $-3.00^{* *}$ \\
\hline & Control & $19.00(6.98)$ & $18.17(6.37)$ & -1.93 \\
\hline & $Z$ & -.20 & & \\
\hline \multirow{3}{*}{ Equanimity } & Experiment & $15.58(5.71)$ & $22.58(4.64)$ & $-2.95^{* *}$ \\
\hline & Control & $12.50(5.23)$ & $12.83(4.93)$ & -.45 \\
\hline & $Z$ & -1.36 & & \\
\hline \multirow{3}{*}{ Perseverance } & Experiment & $17.75(6.18)$ & $23.67(3.98)$ & $-2.71^{* *}$ \\
\hline & Control & $16.67(7.36)$ & $16.83(7.21)$ & -.18 \\
\hline & $Z$ & -.46 & & \\
\hline \multirow{3}{*}{ Authenticity } & Experiment & $15.08(5.12)$ & $22.33(4.94)$ & $-3.07^{* *}$ \\
\hline & Control & $18.50(6.07)$ & $17.58(6.20)$ & -1.51 \\
\hline & $Z$ & -1.72 & & \\
\hline \multirow{3}{*}{ Total } & Experiment & 83.67 (27.77) & $115.00(21.15)$ & $-3.06^{* *}$ \\
\hline & Control & $81.58(26.08)$ & $80.58(24.94)$ & -1.59 \\
\hline & $Z$ & -.40 & & \\
\hline
\end{tabular}

${ }^{*} p<.05, \quad{ }^{* *} p<.01$ 
Journal of Symbols \& Sandplay Therapy, Vol.11 No.2.

\section{Narrative Themes in Sandplay Therapy}

In the group sandplay therapy, the seven categories of narrative themes extracted from the analysis were as follows: magical wish fulfillment, or hope for recovery; danger of disaster; relationship with gods revealing human's identity; desire for protection and care from danger and damages; peaceful relationships without people and nature; creation of a new world and return to normal daily life. Although the sessions in which these themes were manifest varied slightly for each participant, the themes appeared in the order mentioned above for most of them. This statement was especially true for the themes in the latter half.

\section{Magical Wish Fulfillment Meaning Hope for Recovery}

The participants expressed fantasies in which their magical wishes were fulfilled in such forms as becoming queens, Santa giving gifts, unicorns, favorite cars, and riding trains. The participants represented their wish that the miserable situation they were in was not a reality through magical figures such as beautiful queens, a Santa, unicorns and mythical beings. They also depicted wish-fulfillment through things they wanted to have such as cars and nice clothes as well as experiences they wanted to enjoy. It seemed the magical wish fulfillment was a means of psychological compensation for those things that were destroyed by the earthquake. It is worth noting that this magical wish fulfillment represents their recovery from the destruction of the earthquake. The imagination fills in the gap in reality to some extent.

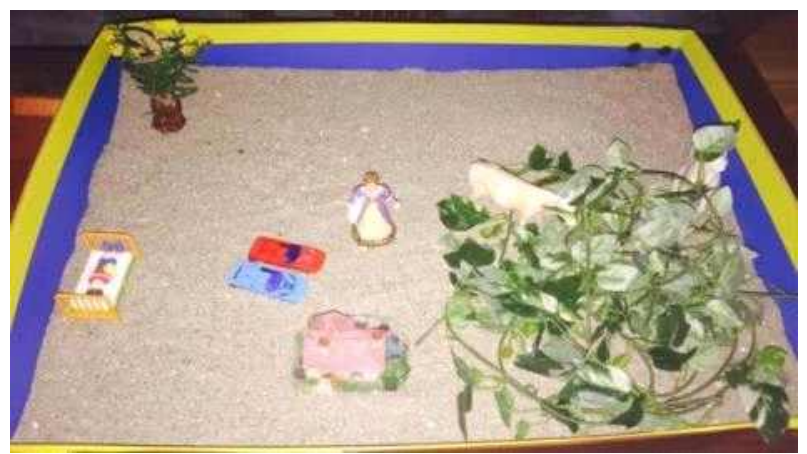

Fig 1. Sandpicture of Adolescent Female E (Session 2) 
"There's Santa giving gifts, and gold coins keep coming out'. I'm happy because I think it is a house I made." (Adolescent Female D, Session 5)

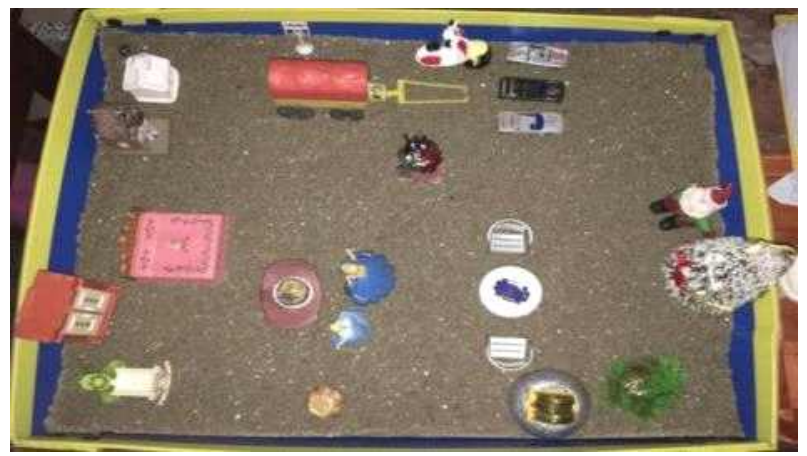

Fig 2. Sandpicture of Adolescent Female D (Session 5)

\section{Direct Expression of Danger of Disaster}

The theme of danger appeared to be directly related to the participants' experiences during the earthquake. The earthquake was expressed as a dangerous object or figure that could appear at any time. Within the psychologically safe and protected space provided by sandplay therapy, the participants recreated the devastation and suffering caused by the earthquake instead of avoiding or denying it as a defense mechanism, which is ultimately unhealthy. They also represented the earthquake as archaic animals and specifically retold the dangers of the earthquake, which they feared could reoccur unexpectedly (Jordan, Perryman, \& Anderson, 2013).

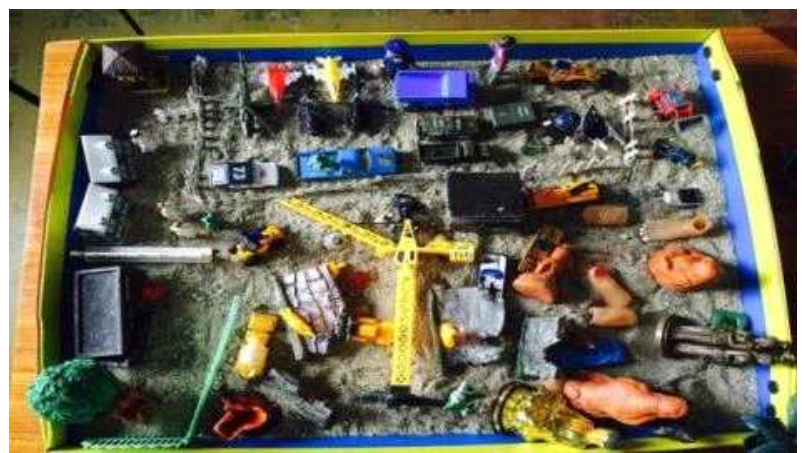

Fig 3. Sandpicture of Adolescent Male B (Session 3) 
Journal of Symbols \& Sandplay Therapy, Vol.11 No.2.

"This is an earthquake scene. A lot of people died and got hurt. Some kids are too young to do anything on their own and die." (Adolescent Male B, Session 3)

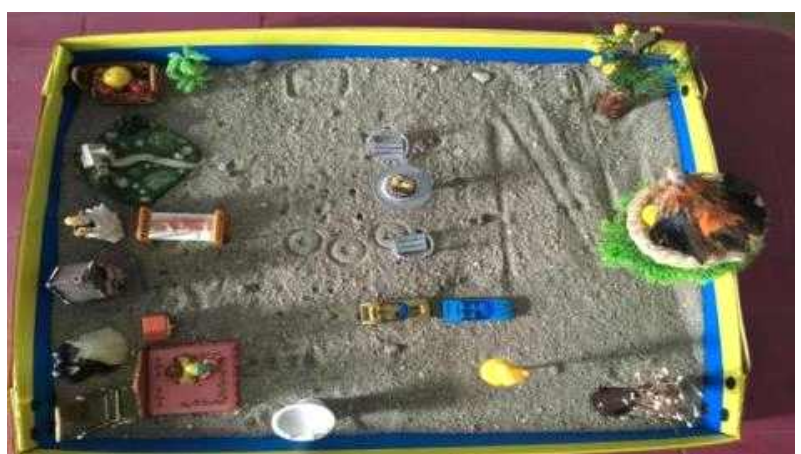

Fig 4. Sandpicture of Adolescent Female F (Session 2)

"The ground is dangerous. It shakes, and the other birds were bothering their babies so they came up eventually." (Adolescent Female F, Session 2)

\section{Relationship with Gods Revealing Human's Identity}

All of the participants who were either Hindu or Buddhist, expressed gods or goddesses and their relationship to humans. Furthermore, every participant put at least one divine figure such as Shiva, Buddha, the Hindu divine symbol of a cow, or temple figures in their sandtrays. They also expressed notions such as gods being everywhere, Buddha in training, grazing cattle, a black statue of Shiva, and a person praying to a god.

Hindus believe that natural disasters are brought on by the will of their gods, hence the participants identified themselves as human beings who are entirely submissive to them and who must accept earthquakes as part of their lives. Therefore, recovering from the damage of disaster is totally up to the gods through praying to the gods and by accepting the gods' will as to how and by whose help they will recover. Adolescent survivors created scenes of praying to their gods or searching for the statues of these gods among the debris, all of which represents their way of recovering from the damage caused by the earthquake. 


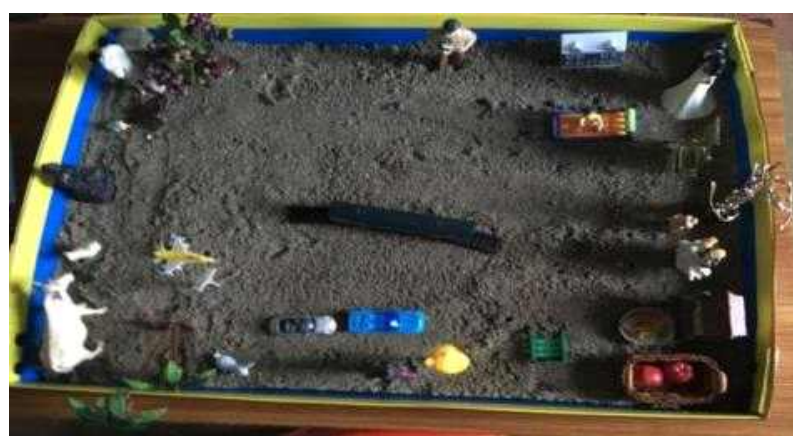

Fig 5. Sandpicture of Adolescent Female F (Session 1)

[Sighing and pointing at a black Shiva statue, the participant said,] "The destination is over there, but there are no more railroads, so the train cannot go any further." (Adolescent Female F, Session 1)

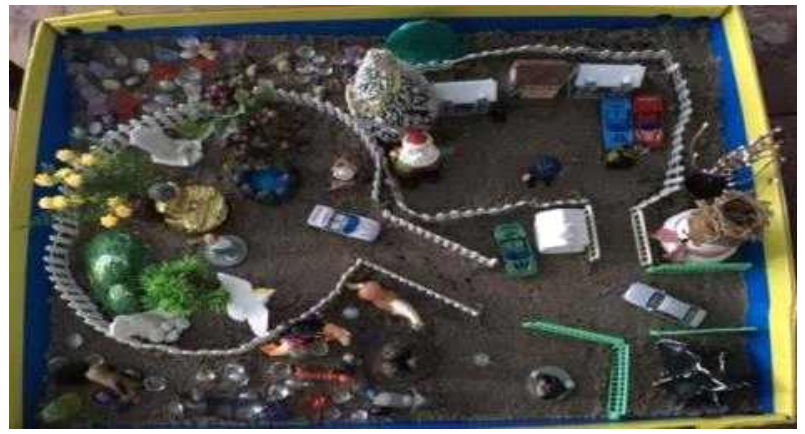

Fig 6. Sandpicture of Adolescent Male K (Session 1)

"People come to see Buddha!" (Adolescent Male K, Session 1)

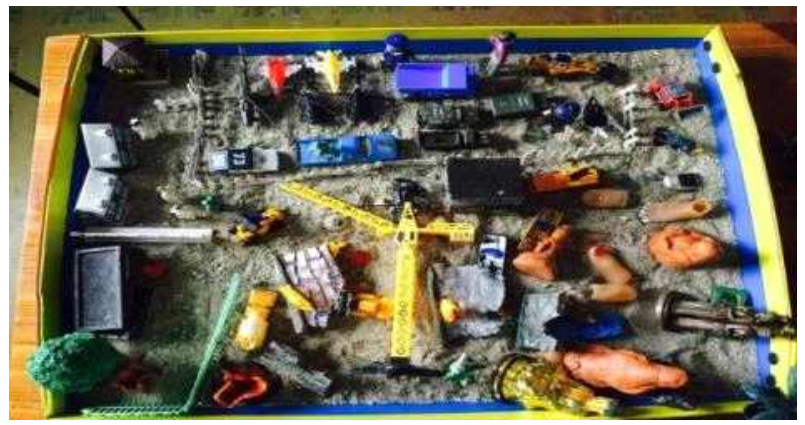

Fig 7. Sandpicture of Adolescent Male B (Session 3) 
Journal of Symbols \& Sandplay Therapy, Vol.11 No.2.

[The participant pointed to a Shiva statue that had collapsed in an earthquake,I "Here, too, the place where Shiva is has also fallen.' (Adolescent Male B, Session 3)

\section{Desire for Protection and Care from Danger and Damage in Reality}

The desire for protection and care was expressed in such forms as police protecting individuals or arresting thieves, struggling soldiers, mother birds seeking food for their babies, prepared food, a mother cooking, and a basket full of fruit. The survivors placed in their sand pictures baby-like beings that needed to be taken care of after a terrible natural disaster, food that symbolizes care, or beings that can protect weak human beings like themselves (Jang \& Lee, 2017).

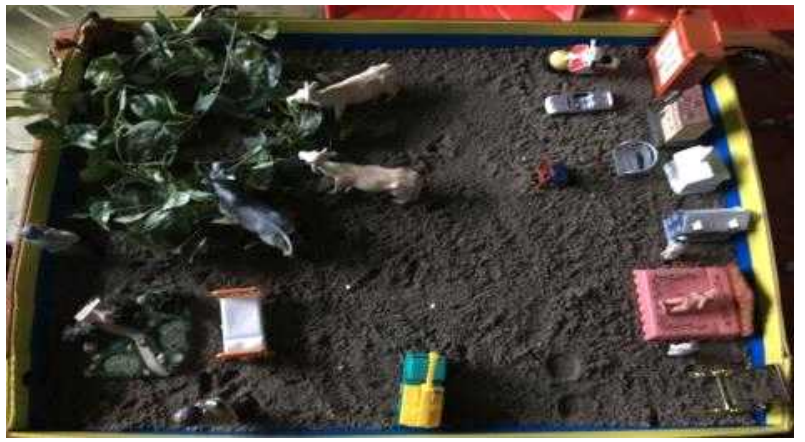

Fig 8. Sandpicture of Adolescent Female F (Session 2)

"The baby is crying because she wants to have her milk." (Adolescent Female F, Session 2)

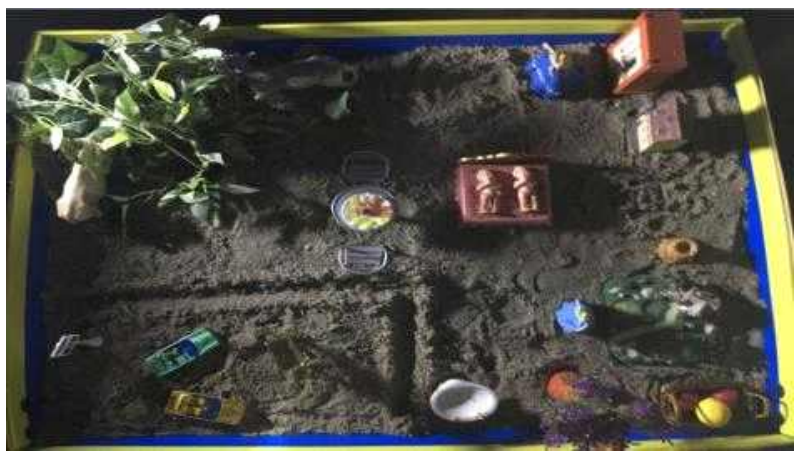

Fig 9. Sandpicture of Adolescent Female E (Session 3) 
"There is fruit on the coconut tree, so I picked it and filled the basket!" (Adolescent Female E, Session 3)

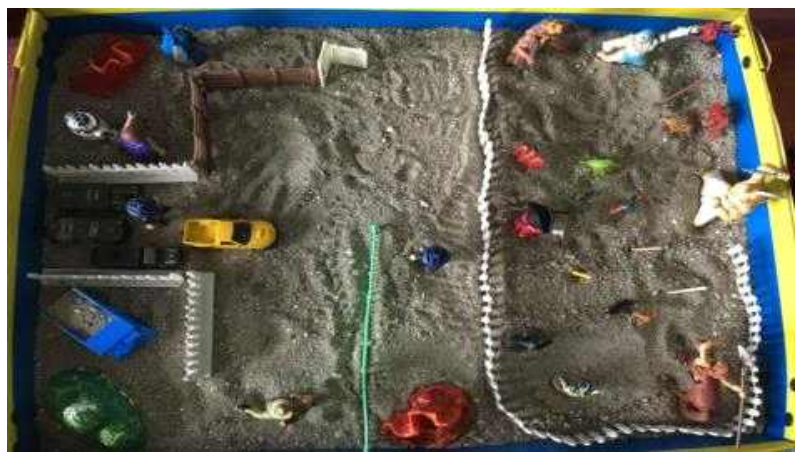

Fig 10. Sandpicture of Adolescent Male B (Session 5)

"The aliens came down to see the volcano, and the soldiers and police are fighting against them for us." (Adolescent Male B, Session 5)

\section{Recovering Order of Life from Chaos}

At the beginning of the sandplay process, the participants mostly created pictures that represented chaos not only in their outer life (e.g., villages and communities destroyed by the earthquake) but also in their inner life (e.g., their confused emotional state). Although there were differences at an individual level, the participants at some point began to place boundary figures, which provide separation from the chaos caused by the earthquake and thus represent

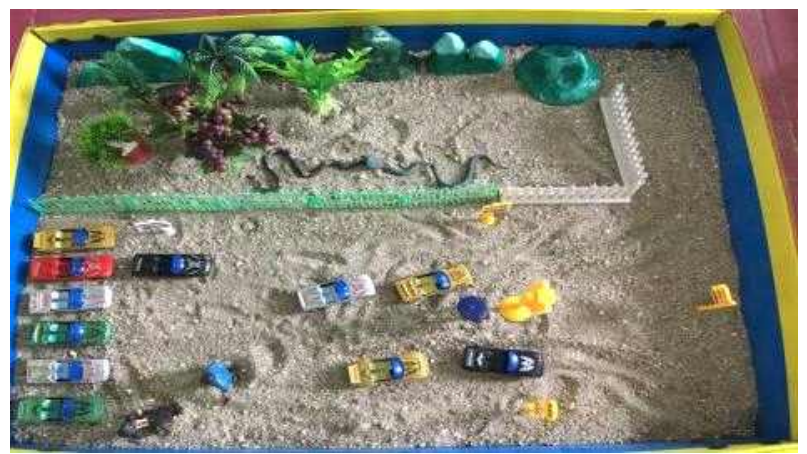

Fig 11. Sandpicture of Adolescent Male J (Session 6) 
Journal of Symbols \& Sandplay Therapy, Vol.11 No.2.

recovery from chaos (Kalff, 1980/2003), in their sand pictures. Boundaries were expressed in such forms as a fence, the divide between nature and cities, rooms in a house, the inside and outside of a house and village, signs of direction, and speed limit signs.

"The above is Himalayan nature, and below is a flea market. This fence lets us know that the places are different. Here is a sign that says, don't go in, it's a dangerous place! The cars see the sign and move." (Adolescent Male J, Session 6)

\section{Creation of a New World from the Chaotic World}

The participants expressed the theme of the creation of a new world, the symbolic meaning of which was the opposite of the destruction and chaos they had witnessed. This theme was expressed in such forms as a safe and clean house, a new road, the green light of life, a flower tree, and ideal future families. The new space or future depicted in the new world is different from the state of chaos and destruction which indicates that order is being restored in the participants' future, that is, they are entering a new world which means a psychological transformation from a traumatized life to a new one (Kalff, 1980/2003).

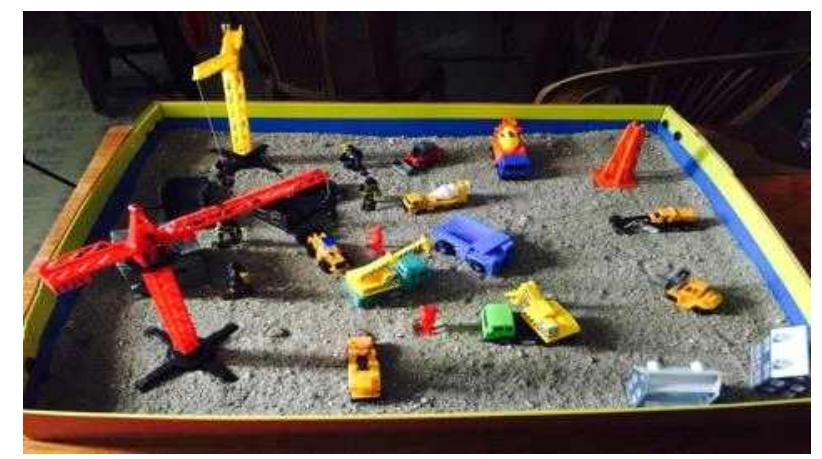

Fig 12. Sandpicture of Adolescent Male H (Session 4)

"The old house has been torn down. And a solid new house is being built there." (Adolescent Male H, Session 4) 


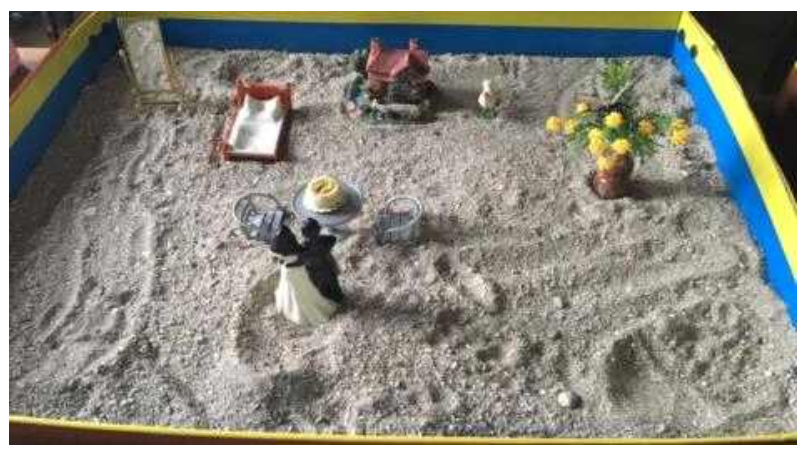

Fig 13. Sandpicture of Adolescent Female D (Session 6)

"This couple is my future. They have a solid house with a lot of sunlight. I think we met so that the house in my heart also becomes solid." (Adolescent Female D, Session 6)

\section{Return to Normal Daily Life}

The theme of daily life seemed to signify the return from chaos to an ordinary life, meaning that the participants have recovered at least partially from their psychological damage (Kalff, 2003). It was expressed in such forms as people working in the city, online transactions, fathers going to work, mothers caring for a child, children going to school, and comments about cars on the roads. The ultimate goal of trauma counseling is to help survivors return to their daily lives, and so the various scenes of everyday life in their sand pictures suggest that the participants are breaking free from the psychological chaos they have suffered as a result of the earthquake (Kalff, 1980/2003; Shelby \& Tredinnick, 1995).

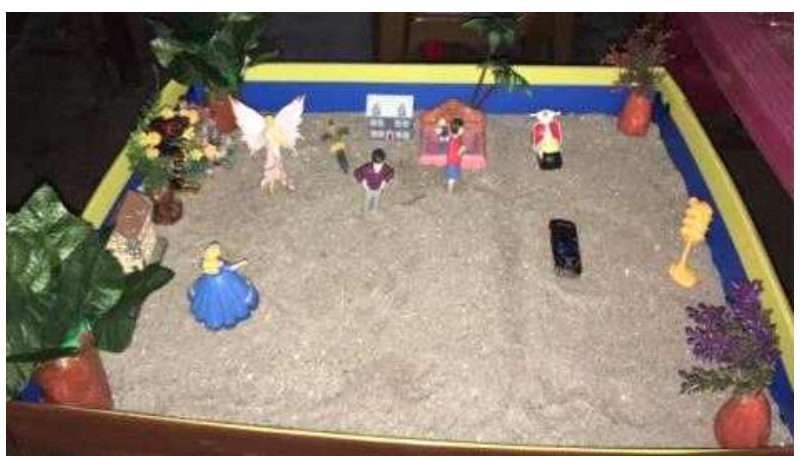

Fig 14. Sandpicture of Adolescent Female E (Session 5) 
"The dad is going to work. And the mom is greeting the dad going off to work." (Adolescent Female E, Session 5)

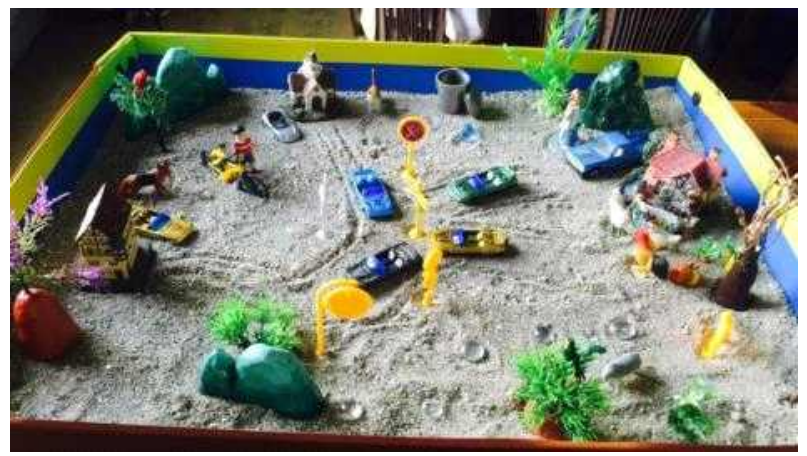

Fig 15. Sandpicture of Adolescent Male L (Session 5)

"There is a house, and next to it there is a chicken, a child going to school, a person washing a car' ${ }^{\prime}$ Everything has its own routine." (Adolescent Male L, Session 5)

\section{Discussion}

This study analyzed the effects of group sandplay therapy on the psychological health and resilience of adolescent earthquake survivors who had been living in temporary relief camps for 16 months after the 2015 Nepal earthquake. In terms of psychological health, the group sandplay therapy led to significant improvements in the anxiety/depression, withdrawal/depression, somatic symptoms, and total internalizing problem scores of the CBCL 6-18. As for resilience, which was measured via the Resilience Scale-25, we observed significant improvements in the subdomains of self-reliance, purpose, equanimity, perseverance, and authenticity. Other studies, although not conducted on adolescents, that yielded similar results are those that administered sandplay therapy on earthquake survivors in Nepal (Hwang, 2017) and in China (Shen \& Lan, 2011). They, too, observed that sandplay therapy enhanced the participants' psychological health and resilience.

The results of our study suggest that the support of caring non-parent adults as one of the external or community factors (Walsh, 2002) is effective, especially for adolescents whose parents 
do not have the ability to support them, whether due to a natural disaster or lack of community resources (Wang, Nan, \& Zhang, 2017; Lee et al., 2013; Salloum et al., 2009; Everall, Altrows \& Paulson, 2006). Therefore, it is assumed that counseling or counselors' support can be one of the resilience factors because post-traumatic stress disorder PTSD and other psychological health problems experienced by survivors of natural disasters such as earthquakes tend to be offset by resilience factors (Kukihara et al., 2014; Jang \& Yoo, 2014; Stein, 2009).

We also found the method of collective intervention to be effective. As Park and colleagues (2014) and Salloum and colleagues (2009) have shown, the group intervention process of sharing can reduce feelings of isolation and negative emotions caused by the trauma, as well as allow a social comparison of traumatic wounds, through which a reduction in anxiety may occur. Thus, the opportunity for self-expression in group sandplay afforded the Nepalese adolescents a voice, with their verbal expressions emphasizing a safe and protected space.

Our qualitative analysis of the participants' verbal expressions yielded seven themes: magical wish fulfillment, or hope for recovery; direct expression of danger of disaster; relationship with gods revealing human's identity; desire for protection and care from danger and damage in reality; recovering the order of life from chaos; creation of a new world from the chaotic world; and return to daily life.

The results of our study are consistent with a previous study that combined quantitative and qualitative analysis to examine the effects of sandplay therapy on children in a school setting after the September 11 attacks. This other study also divided the themes that emerged in sandplay therapy into dominant themes and sub-themes. Similarly, the themes that it identified were those that dealt with the psychological damage from the disaster in question and the subsequent recovery or transformation process (Yeh, Aslan, Mendoza, \& Tsukamoto, 2015).

The participants in our study with Nepalese adolescents symbolically represented not only the chaos and the negative psychological effects brought by the earthquake but also their experiences of going back to everyday life. The themes that appeared mostly at the beginning of the process were the earthquake itself, the destructiveness of the earthquake, and a magical wish fulfillment which compensated for things that were destroyed. There were also religious themes, which suggested that the earthquake occurred by the will of the gods and that one could recover from the disaster only by praying to the gods with sincerity. 
Journal of Symbols \& Sandplay Therapy, Vol.11 No.2.

Although there were no real changes in their outer life - i.e., they still did not have a house to live in and their parents had no stable jobs - the participants created scenes of returning to everyday life. Such an outcome could have been influenced by their Hindu beliefs, that is, despite the difficulties brought about by the earthquake, they may accept it as the will of the gods. Indeed, the creation of a "new world" and the "return to daily life" is usually perceived in sandplay therapy to be a sign of psychological healing (Kalff, 2003).

A previous study, which examined the sand pictures of children who were evacuated from South Asia to Canada two weeks after a tsunami, revealed some common themes with our narrative analysis, such as the experience of the disaster, the notion of gods allowing the disaster to occur, deaths, and soldiers and weapons fighting against destruction (Lacroix et al., 2007). In another sandplay study, on child survivors of the 2011 Tohoku earthquake in Japan, the participants similarly expressed chaos related to the disaster, the involvement of gods, and the recovery of order and daily life (Kawai, 2015).

Lastly, we found in our research that the Nepalese adolescent males and females expressed themselves very differently in their sand pictures. The males typically expressed the earthquake in a direct manner, and took a more problem-solving viewpoint, such as restoring the destruction caused by the earthquake. On the other hand, perhaps due to their belief that they had no obligation or authority to solve the problem, the females tended to express solutions from a more personal perspective, such as marrying a wealthy man with a strong house that cannot be destroyed by earthquakes.

\section{Conclusion}

It is necessary to increase resilience within survivors of natural and other disasters in order to overcome the stress caused by disaster trauma and subsequent long-term residence in adverse conditions. However, the lack of mental health services in developing countries such as Nepal is a factor that exacerbates the negative impact of disasters on survivors, especially children and adolescents. Counseling support, beginning with initial consultation services through a primary care system, should be provided to mitigate the psychological damage to them.

Group sandplay therapy appears to be effective in improving the psychological health and 
resilience of adolescent survivors. Unfortunately, a direct comparison between this study and previously reported studies cannot be made because of a lack of quantitative research on the effects of group sandplay therapy on survivors of natural and other disasters. Nevertheless, the qualitative research that we have presented is notably consistent with the findings of a study that combined quantitative and qualitative analysis to examine the effects of sandplay therapy for children in a school setting after the September 11 attacks.

The results of our study also support the view that gender, age, socioeconomic, religious, and cultural identities have influence on mental health outcomes, and therefore counselors need to understand their clients in the context of the communities and cultures to which they belong. The fact that most participants of this study were either Hindu or Buddhist highlights how important it is for counselors to be aware of the therapeutic effect of spirituality during counseling, and that counselor training and supervision should emphasize how to deal with a client's spiritual aspect. Despite the lack of social services and social infrastructure networks that would help facilitate the recovery of survivors of the 2015 Nepal earthquake, the fact that our group sandplay intervention with adolescent survivors yielded positive outcomes in terms of psychological health and reliance leads us to conclude that the counselor's accepting attitude of a client's religious/cultural context is a key factor in successful counseling.

\section{References}

Bal, A. (2008). Post-traumatic stress disorder in Turkish child and adolescent survivors three years after the Marmara earthquake. Child and Adolescent Mental Health, 13(3), 134-139. doi: $10.1111 / \mathrm{j} .1475-3588.2007 .00469 . x$

Bae, J. Y. (2016). Disaster psychological support for post-traumatic growth. Seoul: Jeong-dam Media.

Bensimon, M. (2012). Elaboration on the association between trauma, PTSD and posttraumatic growth: The role of trait resilience. Personality and Individual Differences, 52, 782-787. doi:10.1016/j.paid.2012.01.011

Bogdan, R. C., \& Biklen, S. K. (2006). Qualitative research for education: an introduction to theories and methods (5th Ed.). Boston: Allyn \& Bacon.

Bradway, K., Signell, K., Spare, G., Stewart, C. T., \& Stewart, L. H. (1980/1990). Sandplay studies: 
Journal of Symbols \& Sandplay Therapy, Vol.11 No.2.

Origins, theory and practice. Boston: Sigo.

Carey, L. (1999). Sandplay therapy with children and families. New York: Rowman \& Littlefield Publishing Company.

Creswell, J. W., \& Plano Clark, V. L. (2007). Designing and conducting mixed methods research. Thousand Oaks, CA: Sage.

Davidson, J. R., \& McFarlane, A. C. (2006). The extent and impact of mental health problems after disaster. Journal of Clinical Psychiatry, 67(2), 9-14.

Deeba, F., \& Rapee, M. (2015). Prevalence of traumatic events and risk for Psychological symptoms among community and at-risk children and adolescents from Bangladesh. Child and Adolescent Mental Health, 20(4), 218-224. doi: 10.1111/camh.12093

DiGiorgio, K. E., Arnkoff, D. B., Glass, C. R., Lyhus, K. E., \& Walter, R. C. (2004). EMDR and Theoretical Orientation: A Qualitative Study of How Therapists Integrate Eye Movement Desensitization and Reprocessing Into Their Approach to Psychotherapy. Journal of Psychotherapy Integration, 14(3), 227-252. doi: 10.1037/1053-0479.14.3.227

Dumont, T. F., \& Provost, M. A. (1999). Resilience in adolescents: protective role of social support, coping strategies, self-esteem, and social activities on experience of stress and depression. Journal of Youth and Adolescents, 28, 343-363. doi: 10.1023/A:1021637011732

Everall, R. D., Altrows, J. a., \& Paulson, B. (2006). Creating a future: A study of resilience in suicidal female adolescents. Journal of Counseling and Development, 84, 461-470. doi: 10.1002/j.1556-6678.2006.tb00430.x

Eversohn, L., \& Loots, M. N. T. (2017). Analysing risk and resilience in the first sand tray of youth at a rural school. Arts in Psychotherapy, 55, 146-157. doi:org/10.1016/j-aip.2017.04.007

Feeny, N. C., Foa, E. B., Treadwell, K. R., \& March, J. (2004). Post-traumatic Stress Disorder in Youth: A Critical Review of the Cognitive and Behavioral Treatment Outcome Literature. Professional Psychology: Research and Practice, 35(5), 466-476. doi: 10.1037/0735-7028.35.5.466

Fernando, D. M., \& Hebert, B. (2011). Resiliency and recovery: Lessons from the Asian tsunami and hurricane Katrina. Journal of Multicultural Counseling and Development, 39, 2-13. doi: $10.1002 / j .2161-1912.2011 . t b 00135 . x$

Furukawa, H., Takeuchi, T., Yano, E., \& Muto, S. (2015). Factors influencing psychological distress after the Great East Japan Earthquake and tsunami. Journal of Community Psychology, 43(5), 521-526. doi: 10.1002/jcop.21695

Gadamer, H.-G. (1975). Truth and method. New York: Crossroad.

Garza, Y., Monakes, S., Watts, R. E., \& Wiesner, V. (2011). Implementing Adlerian sand tray 
Lee, SeHwa $\cdot$ Jang, Mikyung / The Effect of Group Sandplay Therapy on Psychological Health and Resilience of Adolescent Survivors of Nepal Earthquake

therapy with adult male substance abuse offenders: A phenomenological inquiry. Journal of Addictions \& Offender Counseling, 31(2), 94-107. doi: 10.1002/j.2161-1874.2011.tb00070.x

Greene, J. C., Caracelli, V. J., \& Graham, W. F. (1989). Toward a conceptual framework for mixed-method evaluation designs. Educational Evaluation and Policy Analysis, 11, 255-274. doi:10.3102/01623737011003255

Gu, B. Y. (2011). Disaster-affected youth intervention manual. Korea Youth Counseling Institute.

Han, H. H. (2010). Hinduism, the views of nature and ecological ethics. Journal of the Korean Society for the Study of Environmental Philosophy, 9, 145-176.

Hauser, S. T. (1999). Understanding resilient outcomes: Adolescent lives across time and generations. Journal of Research on Adolescents, 9, 1-24. doi: 10.1207/s15327795jra0901_1

Hong, K. U. (2005). Pediatric psychiatry. Seoul: Hakjisa.

Howard, s., \& Johnson, B. (2000). What makes the difference? Children and teachers talk about resilient outcomes for children "at risk." Educational Studies, 26, 321-337.

doi: $10.1080 / 03055690050137132$

Hwang, H-J. (2017). The effect of parent group sandplay therapy on the Nepal earthquake survivors: Post-traumatic stress symptoms, parenting stress and psychological well-being of parents as well as post-traumatic stress symptoms in children. Journal of Symbols and Sandplay Therapy, $8(2)$, 57-70. doi: $10.12964 /$ jsst. 170008

Hwang, H-J., \& Kim, H. Y. (2017). The effect of parent group sandplay therapy on parenting stress, psychological well-being of parent and post-traumatic stress symptoms of Nepal earthquake child and parent survivors. Paper presented at the 24th Congress of the International Society for Sandplay Therapy, Kalua-Kona, Hawaii.

Jang, M., Ko, J-A., \& Kim, E-J. (2018). Religion and mental health among Nepal earthquake survivors in temporary tent villages. Mental Health, Religion \& Culture, 21(4), 329-335. doi: org/10.1080/13674676.1485136

Jang, M., \& Lee, S-H. (2017). Destruction and creation in sandplay of earthquake survivors in Nepal. $24^{\text {th }}$ International Congress of Sandplay Therapy. International Society of Sandplay Therapy.

Jang, M., \& Kim, Y-H. (2012). The effect of group sandplay therapy on the social anxiety, loneliness and self-expression of migrant women in international marriages in South Korea. Arts in Psychotherapy, 391), 38-41. doi: 10.1016/j.aip.2011.11.008

Jang, E. R., \& Yoo, S. E. (2014). Resilience and suicidal behavior in adults with traumatic life events. Korean Journal of Clinical Psychology, 33(2), 299-314.

Jiang, S., Yan, Z., Jing, P., Li, C., Zheng, T., \& He J. (2016). Relationships between sleep 
Journal of Symbols \& Sandplay Therapy, Vol.11 No.2.

problems and psychiatric comorbidities among China's Wenchuan Earthquake survivors remaining in temporary housing camps. Frontiers in Psychology, 7, 1-8.

Jordan, B., Perryman, K., \& Anderson, L. (2013). A case study child-centered play therapy with natural disaster and catastrophic event survivors. International Journal of Play Therapy, 22(4), 219-230. doi: 10.1037/a0034637

Jordans, M.J., Keen, A.S., Pradhan, H., Tol, W.A. (2007). Psychosocial counseling in Nepal: Perspectives of counselors and beneficiaries. International Journal for the Advancement of Counseling, 29(1), 57-68. doi.org/10.1007/s10447-006-9028-z

Johnson, (2004). Reconceptualising the visual in narrative inquiry into teaching. Teaching and Teacher Education, 20, 5, 423-434. doi: org/10.1016/j.tate.2004.04.009

Jung, E. M. (2015). Indirect trauma response by media exposure of Sewol Ferry Disaster in university students in Korea: trauma-related negative beliefs as moderating variables (Unpublished master's thesis). Daegu University, Daegu, South Korea.

Kalff, D. M. (1980/2003). Sandplay: A psychotherapeutic approach to the psyche. Cloverdale, CA: Temenos Press.

Kawai, T. (2015). Big stories and small stories in the psychology relief work after the earthquake disaster: Life and death. In Huskinson, L. \& Stein, M., Analytical psychology in a changing world: The search for the Self, identity and community. New York: Routledge.

Korean Disaster \& Trauma Mental Health Committee (2015). Disaster and mental health. Seoul: Hakjisa.

Kukihara, H., Yamawaki, N., Uchiyama, K., Arai, S., \& Horikawa, E. (2014). Trauma, depression, and resilience of earthquake/tsunami/nuclear disaster survivors of Hirono, Fukushima, Japan. Psychiatry and Clinical Neurosciences, 68(7), 524-533. doi: 10.1111/pcn.12159.

Lacroix, L., Rousseau, C., Gauther, M., Singh, A., Giguere, N., \& Lemzoudi, Y. (2007). Immigrant and refugee preschoolers' sandplay representation of the tsunami. Arts of Psychotherapy, 34(2), 99-113. doi: org/10.1016/j.aip.2006.09.006

Landreth, G. L. (2012). Play therapy: The art of the relationship. New York: Routledge.

Lee, J. H., Nam, S. K., Kim, A-R., Kim, B., Lee, M. Y., Lee, S. M. (2013). Resilience: a meta-analytic approach. Journal of Counseling and Development, 91, 269-279. doi: $10.1002 / j .1556-6676.2013 .00095 . x$

Li, M-H., \& Yang, Y. (2016). A cross-culture study on a resilience-stress path model for college students. Journal of Counseling and Development, 94, 319-332. doi: 10.1002/jcad.12088

Lincon, Y. S. \& Guba, E. G. (1985). Naturalistic inquiry. Beverly Hills, CA: Sage. 
Lee, SeHwa $\cdot$ Jang, Mikyung / The Effect of Group Sandplay Therapy on Psychological Health and Resilience of Adolescent Survivors of Nepal Earthquake

McAdams, C. R., \& Keener, H. J. (2008). Preparation, action, recovery: A conceptual framework for counselor preparation and response in client crisis. Journal of Counseling and Development, 86, 388-398. doi: 10.1002/j.1556-6678.2008.tb00526.x

Marotta, S. (2000). Best practice for counselors who treat posttraumatic stress disorder. Journal of Counseling and Development, 78, 492-495. doi: 0.1002/j.1556-6676.2000.tb01933.x

Mathis, C. R. (2001). The story of a sexually abused child's sandplay: A single case study. (Doctoral dissertation). Falls Church, VA: Virginia Polytechnic Institute \& State University.

Moon, P. (2006). Sand play therapy with U. S. soldiers diagnosed with PTSD and their families. VISTAS Counseling Veterans and Military Families. Accessed on 9 September, 2018. https://www.counseling.org/knowledge-center/vistas/by-subject2/vistas-veterans/docs/default-source/vista s/sand-play-therapy-with-u-s-soldiers-diagnosed-with-ptsd-and-their-families

Morris, A., Gabert-Quillen, C., \& Delahanty, D. (2012). The association between Parent PTSD/ Depression symptoms and child PTSD symptoms: A meta-analysis. Journal of Pediatric Psychology, 37(10), 1076-1088. doi: 10.1093/jpepsy/jss091

Morton, M., \& Levy, J. L. (2011). Challenges in disaster data collecting during recent disasters. Prehospital and Disaster Medicine. 26(3), 196-201. doi: 10.1017/S1049023X11006339

Nepal Planning Commission (2015). Nepal earthquake 2015: Post disaster need assessment Vol. B: sector reports. Nepal Planning Commission.

Okuyama, J., Funakoshi, S., Tomita, H., Yamaguchi, \& T., Matsuoka, H. (2017). Mental health and school-based intervention among adolescent exposed to the 2011 Great East Japan Earthquake and tsunami. International Journal of Risk Reduction, 23, 183-188.

doi: $10.1016 /$ j.ijdrr.2017.06.012

Oyama, M., Nakamura, K., Suda, Y., \& Someya, T. (2012). Social network disruption as a major factor associated with psychological distress 3 years after the 2004 Niigata-Chuetsu earthquake in Japan. Environmental Health and Preventive Medicine, 17(2), 118-123.

doi: 10.1007/s12199-011-0225-y

Park, B. K. (2013). The relationship between resilience of college students, meaning of life, intentional rumination and post-traumatic growth (Unpublished master's thesis). Kyungpook National University, Daegu, South Korea.

Park, S. H., Kim, J. Y., Kim, R. J., Jeon, G. I., Ji, K. J., \& Hwang, H. K. (2014). Mental health in childhood. Gyeonggi: YangSeoWon Publishing.

Plotts, C. Lasser, J., \& Prater, S. (2008). Exploring sandplay therapy: Application to individuals with traumatic brain injury. International Journal of Play Therapy, 17(2), 138-153. 
Journal of Symbols \& Sandplay Therapy, Vol.11 No.2.

doi: $10.1037 / 1555-6824.17 .2 .138$

Rak, C. F., \& Patterson, E. (1996). Promoting resilience in at-risk children. Journal of Counseling and Development, 74, 368-373. doi: 10.1002/j.1556-6676.1996.tb01881.x

Ratts, J. M., Singh, A. A., Nassar-McMillan, Butler, S. K., \& McCullough, J. R. (2016). Multicultural and social justice counseling competencies: Guild lines for the Counseling profession. Journal of Multicultural Counseling and Development, 44, 28-49. doi: 10.1002/jmcd.12035

Reyes, C. J. (2003). Combining art and sandtray therapies with sexually abused children. In $\mathrm{H}$. Kaduson and C. Schaefer (Eds.), 101 favorite play therapy techniques (3rd ed.). pp. 125-128. Northvale, NJ: Jason Aronson.

Richman, J. M., \& Fraser, M. W. (2001). Resilience in childhood: The role of risk and protection. In J. M. Richman \& M. W. Fraser (Eds.), The contest of youth violence: Resilience, risk, and protection (pp. 1-12). Westport, CT: Praeger.

Risler, E., Kintzle, S., \& Nackerud, L. (2015). Haiti and the earthquake: Examining the experience of psychological stress and Trauma. Research on Social Work Practice, 25(2), 251-256. doi: $10.1177 / 1049731514530002$

Salloum, A., Garsi9de, L. W., Irwin, C. L., Anderson, A. D., Francois, A. H. (2009). Grief and trauma group therapy for children after hurricane Katrina. Social Work with Groups, 32:1-2, 64-79. doi: 10.1080/01609510802290958

Seidler, G. H., \& Wagner, F. E. (2006). Comparing the efficacy of EMDR and trauma-focused cognitive-behavioral therapy in the treatment of PTSD: a meta-analytic study. Psychological Medicine, 36(11), 1515-1522. doi: 10.1017/S0033291706007963

Shannonhouse, L. R., Barden, S. M., \& McDonald, P. (2017). Mixed Methodology in Group Research: Lessons Learned. Journal for Specialists in Group Work, 42(1): Research in group work: A renewed focus on exemplary methods, part 1, 87-107.

doi:org/10.1080/01933922.2016.1264521

Shelby, J. S., \& Tredinnick, M. G. (1995). Crisis Intervention With Survivors of Natural Disaster: Lessons From Hurricane Andrew. Journal of Counseling and Development, 73, 491-497. doi: 10.1002/j.1556-6676.1995.tb01784.x

Shen, H., \& Lan, G. (2011). The garden of the heart and soul: Psychological relief work in earthquake zones and orphnlanages in China. Spring Journal: Spring 88, 61-74.

Silwal, S., Dybdahl, R., Chudal, R., Sourander, A., \& Lien, L. (2018). Psychiatric symptoms experienced by adolescents in Nepal following the 2015 earthquakes. Journal of Affective Disorders, 234, 239-246. doi: org/10.1016/j.jad.2018.03.002 
Slade, M. K., \& Warne, R. T. (2016). A meta-analysis of the effectiveness of trauma-focused cognitive-behavioral therapy and play therapy for child victims of abuse. Journal of Young Investigators, 306), 36-43. doi: 10.1177/2150137815573790

Stein, D. J. (2009). The psychobiology of resilience. CNS Spectrums, 14, 41-47. doi: $10.1017 / S 1092852900027280$

Sherchan, S., Samuel, R., Marahatta, K., Anwar, N., Ommeren, H. V., \& Ofrin, R. (2017). Post-disaster mental health and psychosocial support: Experience from 2015 Nepal earthquake. WHO South-East Asia Journal of Public Health, Q(1), 22-29. doi: 10.410./2224-3151.206160

Taki-Reece, S., \& Ford, C. (2007). The frontier of group sandplay. Journal of Sandplay Therapy, 16(2), 19-21.

Taki-Reece, S., \& Ford, C. (2006). All the children can group sandplay: Help meet the growing need. Journal of Sandplay Therapy, 15(2), 87-108.

Tanwar, R. (2016). Environment conservation in ancient India. IOSR Journal of Humanities and Social Science, 21 (9), 1-4.

Wagnild G. M., \& Young H. M. (1993). Development and psychometric evaluation of the Resilience Scale. Journal of Nursing Measurement, 1(2), 165-178.

Wang, D., Nan, J. K. M., \& Zhang, R. (2017). Structured group sandplay to improve the resilience of college students: A pilot study. Arts in psychotherapy, 55, 186-194. doi: org/10.1016/j.aip.2017.04.006

World Health Organization (2017). Mental health status of adolescents in South-East Asia: Evidence for action. Regional Office for South-East Asia.

World Health Organization (2006). WHO-AIMS Report on mental health system in Nepal. Ministry of Health and Population Nepal.

Yeh, C., Aslan, S. M., Mendoza, V. E., \& Tsukamoto, M. (2015). The use of sandplay therapy in urban elementary school as a crisis response to the World Trade Center Attacks. Psychology Research, 5(7), 413-427. doi:10.17265/2159-5542.07.004

Yorbik, R., Akbiyik, D. I., Kirmizigul, P., \& Sohmen, T. (2004). Post-traumatic stress disorder symptoms in children after the 1999 Marmara earthquake in Turkey. International Journal of Mental Health, 33(1), 46-58. doi: 10.1080/00207411.2004.11043360

Zappacosta, J. D. (2013). Sandplay therapy: A way of rediscovering inner wisdom in the body and psyche. In S. Loue (Ed.), Expressive therapies for sexual issues. pp. 181-199. New York: Springer.

Zhang, J., Zhu, S., Du, C., \& Zhang, Y. (2015). Post-traumatic stress disorder and somatic symptoms among child and adolescent survivors following the Lushan earthquake in China: A 
Journal of Symbols \& Sandplay Therapy, Vol.11 No.2.

six-month longitudinal study. Journal of Psychosomatic Research, 79, 100-106. doi: 10.1016/j.jpsychores.2015.06.001

투고일 : 2020. 09. 29

수정일 : 2020. 11. 23

게재확정일 : 2020. 12. 22 